\title{
Dermoscopy findings in tinea capitis. Case report and literature review
}

\author{
Achados dermatoscópicos na tinea capitis. Relato de caso e revisão da literatura
}

\author{
Ana Maria Costa Pinheiro ${ }^{1}$ \\ Tatiana Cristina Nogueira Varella ${ }^{3}$
}

\author{
Larissa Araujo Lobato ${ }^{2}$
}

\begin{abstract}
Dermoscopy is a method of increasing importance in the diagnoses of cutaneous diseases. On the scalp, dermoscopic aspects have been described in psoriasis, lichen planus, seborrheic dermatitis and discoid lupus. We describe the "comma" and "corkscrew hair" dermoscopic aspects found in a child of skin type 4 , with tinea capitis.

Keywords: Child; Dermoscopy; Tinea capitis

Resumo: A dermatoscopia é um método que ganha cada vez mais importância na diagnose de diversas dermatoses. No couro cabeludo, já foram descritos os aspectos dermatoscópicos presentes na psoríase, no líquen plano, na dermatite seborréica e no lúpus discóide. Nós descrevemos padrão dermatoscópico de "cabelos em vírgula e em saca rolhas" encontrado em uma criança com fototipo 4, com tinha do couro cabeludo.

Palavras-chave: Criança; Dermatoscopia; Tinha do couro cabeludo
\end{abstract}

\section{INTRODUCTION}

Dermoscopy, in the last thirty years, has been used in dermatology for the identification of different structures and colors not seen by the naked eye. It has been widely used in the diagnosis of pigmented lesions. ${ }^{1}$ However, dermoscopy and videodermoscopy have expanded their role in the diagnosis of skin diseases as psoriasis, alopecia, parasites, nail disorders, collagen diseases and others. ${ }^{2}$ Since then it has been possible to identify disease specific findings. Tinea capitis has different etiological agents and can manifest with one or several areas of alopecia, with or without tonsure. The determination of a specific dermoscopic finding could lead to a straightforward diagnosis.

\section{CASE REPORT}

A five-year-old, healthy, black female patient has developed an itchy, painless patch of alopecia in the right parietal region on the scalp, with slightly scaly and progressive growth, in the past eighteen months. The emergence of other focal areas of alopecia was noticed after onset. A videodermoscopy examination with the Fotofinder ${ }^{R}$ dermoscope under $20 \mathrm{x}$ and $40 \mathrm{x}$ magnification was performed and showed comma hairs and an important amount of corkscrew hairs (Figures 1 and 2). The direct mycological exam and the culture of the collected material identified Tricophyton tonsurans.

\footnotetext{
Received on 23.06.2011.

Approved by the Advisory Board and accepted for publication on 11.10.2011.

* Study carried out at the Outpatient Clinic for Tumors and Dermatoscopy of the Teaching Hospital of Brazilia (Hospital Universitário de Brasília - Universidade de Brasília - HUB-UnB) - Brasília (DF), Brazil.

Conflict of interest: None

Financial funding: None

Master's degree in Dermatology from the University of São Paulo (Universidade de São Paulo - USP) - Professor of Dermatology at the Universidade de Brasília (UnB), Coordinator of the Outpatient Clinic for Tumors and Dermatoscopy of the Teaching Hospital Universitário de Brasília - Universidade de Brasília (HUB-UnB) - Brasília (DF), Brazil.

Physician, Dermatology Resident, Universidade de Brasília (UnB) - Brasília (DF), Brazil.

Volunteer physician at the Teaching Hospital Universitário de Brasília - Universidade de Brasília (HUB-UnB) - Brasília (DF), Brazil.

(C)2012 by Anais Brasileiros de Dermatologia
} 


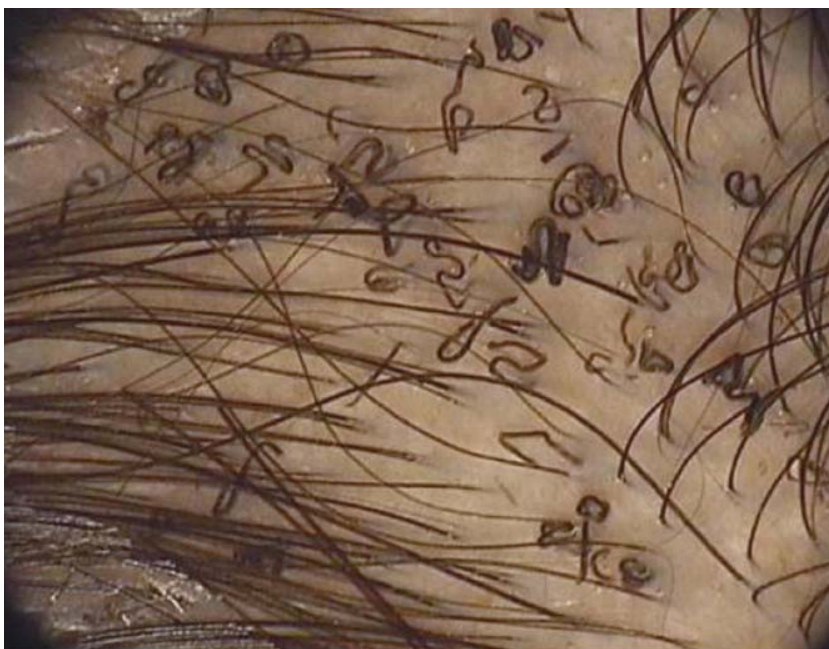

FIGURE 1: Videodermoscopy 20x, comma and corkscrew hair

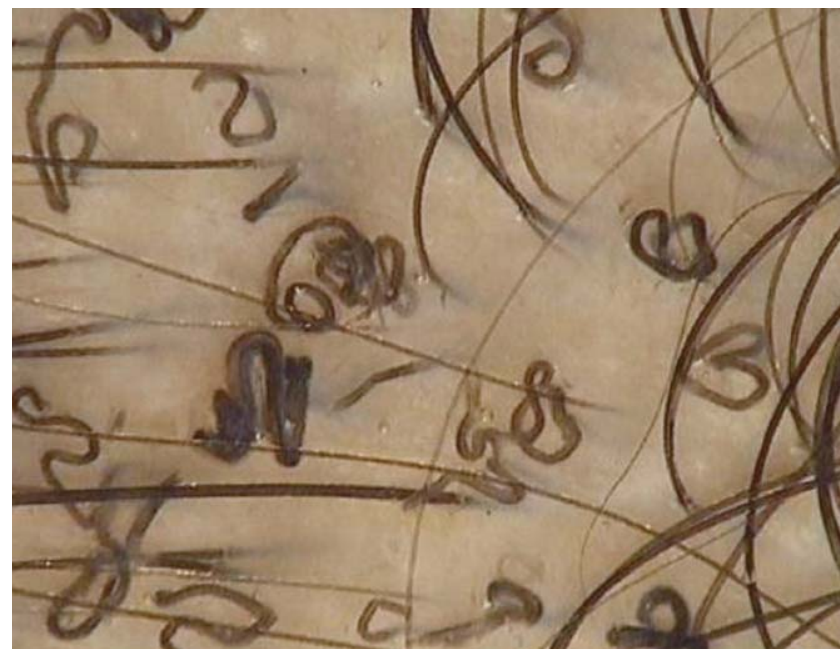

Figure 2: Videodermoscopy 40x. Comma and corkscrew hair

\section{DISCUSSION}

In 2008, Slowinska described in two patients with tinea capitis the presence of comma like structures (comma hair), dermoscopic finding characterized by a pigmented, homogeneously thickened and sharp slating ended hair shaft. ${ }^{3}$ The authors believe that comma hair is probably shaped as a result of subsequent cracking and bending of a hair shaft filled with hyphae. These findings are in contrast with those found in dermoscopy areas of alopecia areata (AA), where exclamation marks, vellus hairs, dystrophic and cadaverized hairs were seen, as yellow dots. In 2010, a study of seven patients with tinea capitis held by Sandoval demonstrated the presence of comma hair in all patients examined. ${ }^{4}$ The tinea capitis was caused by Microsporum canis and Trichophyton tonsurans. In 2011, Hughes described in six black children with diagnosis of tinea capitis the dermatoscopic finding of comma hair and the presence of hair in the shape of a corkscrew. ${ }^{5}$ The authors also noted the presence of dystrophic and broken hair. The fungi were identified as Trichophyton soudanense, Trichophyton violaceum and Microsporum langeronii. The dermoscopic finding of corkscrew hair seems to be a variation of the comma hair, manifesting in black patients. Our patient is a black child and the dermoscopy observed the presence of comma hairs and numerous corkscrew hairs. On dermoscopic examination the comma hairs and the corkscrew hairs appear to be specific dermoscopic findings of dermatophytosis of the scalp, regardless of the etiological agent. It can facilitate the diagnosis, since it is a fast, noninvasive and inexpensive method. $\square$

\section{REFERENCES}

1. Braun PR, Rabinovitz HS, Oliviero M, Kopf AW, Saurat JH. Dermoscopy of pigmented skin lesions . J Am Acad Dermatol. 2005;52:109-21.

2. Micali G, Lacarruba F, editors. Dermoscopy in clinical practice: beyond pigmented lesions. Colchester: Informa Healthcare; 2010. p 1-2.

3. Slowinska M, Rudnicka L, Schwartz RA, Kowalska-Oledzka E, Rakowska A, Sicinska J, et al. Comma hairs: A dermatoscopic marker for tinea capitis. A rapid diagnostic method. J Am Acad Dermatol. 2008;59(5 Supl):S77-9.

4. Sandoval ABC, Ortiz JAS, Rodrígues JM, Vargas AG, Quintero DGV. Hallazgos dermoscópicos en tinea capitis. Rev Iberoam Micol. 2010;27:151-2.

5. Hughes R., Chiaverini C., Bahadoran P, Lacour JP. Corkscrew hair: a new dermoscopic sign for diagnosis of tinea capitis in black children. Arch Dermatol. 2011;147:355-6.

\author{
MAILING ADDRESS: \\ Ana Maria Costa Pinbeiro \\ Hospital Universitário de Brasília \\ Ambulatório de Dermatologia \\ SGAN 605 s/ Numero. \\ 70840-901 Brasília, DF \\ E-mail: anapinbeiro2000@yaboo.com.br
}

How to cite this article: Pinheiro AMC, Lobato LA, Varella TCN. Dermoscopy findings in tinea capitis. Case report and literature review. An Bras Dermatol. 2012;87(2):313-4. 